\title{
Aging, Trade and Migration
}

\author{
Richard Chisik*, Harun Onder, Dhimitri Qirjo
}

June 8, 2015

\begin{abstract}
We consider the role of demand driven changes arising from population aging and how they affect the pattern of international trade as well as trade and immigration policy. An aging society can see a welfare reducing reduction in its share of manufacturing output and this reduction is magnified by a decrease in trade costs (an increase in globalization). Immigration can ameliorate this outcome if it is directed towards younger immigrants. A unilateral tariff increase can also reduce firm delocation from aging country, however, a reciprocated tariff increase will unambiguously harm the country with the older average population.
\end{abstract}

JELClassification: F12, J14, F22

Keywords: Demographic Transition, Consumption, Trade Policy, Immigration Policy.

${ }^{*}$ Corresponding author, Department of Economics, JOR-211, Ryerson University, Toronto, ON, M5B 2K3. E-mail: rchisik@arts.ryerson.edu. Phone: +1-416-979-5000 Ext. 4620 .

†The World Bank, 1818 H Street NW, Washington, DC 20433, Mail-Stop: H 4-402. E-mail: honder@worldbank.org. Phone: +1-202-473-5196.

‡Department of Economics \& Finance, SUNY Plattsburgh, 329 Au Sable Hall, 101 Broad Str., Plattsburgh, NY, 12901. E-mail: dqirj001@fiu.edu. Phone: +1-518-564-4200. 


\section{Introduction}

Population aging is an important stage of the demographic transition and this stage is expected to have strong effects on the structure of the world economy. According to the United Nations (2013) the percentage of the world population over sixty years of age was $8 \%$ in 1950 , has risen to $12 \%$ by 2013 , and is expected to reach $21 \%$ by 2050 . The rate of change will not be the same in all countries. Countries with a younger average population will age faster as they begin to catch up with more senior countries. ${ }^{1}$ In fact, this part of the demographic transition is predicted to be felt most strongly in the least-developed countries. Recognizing its implications for capital-labour ratios, and savings behaviour, economists have begun to look seriously at this stage of the demographic transition. In this paper we propose a new aspect of population aging that has been previously overlooked in the literature: an aged-induced change in consumption patterns.

Our starting point is that the elderly consume more services than the young. For example, a 2013 survey of Canadian households found that expenditures on health care (apart from what is provided by national insurance) comprised $7.6 \%$ of goods and services spending for households headed by a senior aged at least 65 years old and only $2.9 \%$ for a household headed by someone under $30 .^{2}$ In addition to health care, seniors would be more likely to purchase

${ }^{1}$ For example, in Japan $32 \%$ of the population was over 60 in 2013 and the countries in western Europe had between $20 \%$ and $27 \%$ over 60 in 2013.

${ }^{2}$ Oliveira Martins et al. (2005) show that in 2000, the expenditure on the health care in the U.S. (apart from what is provided by national insurance) consists of approximately $3 \%$ of young individuals' total expenditures, and about $12 \%$ of old individuals' total expenditures. They also show that old individuals spend more in the health care sector than the young in other OECD countries. 
personal and household maintenance services than the young. ${ }^{3}$ For example, Desvaux et al. (2010) project the demand of French consumers over the 20072030 time period and show that dwelling, maintenance, and repairs would have a positive annual growth rate of $1.7 \%$ for French consumers aged 65 or older and a negative annual growth rate of $1 \%$ for individuals under $40 .^{4}$ The additional expenditure on services must come at the expense of manufactured goods. As the advertising industry repeatedly emphasizes, the key demographic age for new manufactured goods is between 18 and 54, and not the elderly.

This change in individual consumption patterns has several external effects. Manufactured goods are not only more easily tradable than services they generally have more significant economies of scale. ${ }^{5}$ Hence, age induced changes in domestic consumption can have important effects on the pattern of international trade.

Our basic idea is threefold. First, consumption patterns change with age. Second, services are less tradable than manufactured goods. Third, increased production of manufactured goods generates more production externalities than does services. Hence, an increase in the average age of a country can generate an increased reliance on imported manufactured goods and a consequent reduction in economic growth. We then consider the role of trade and immigration policy in ameliorating any negative outcomes from these demand driven externalities. Although stylized, our model generates clear and sensible policy prescriptions.

\footnotetext{
${ }^{3}$ Most personal and household maintenance services are considered as classic nontradables, however, medical tourism is a growing industry, indicating that health care is not completely untradeable.

${ }^{4}$ Moreover, focusing on fees for legal services, payment of services for estates agents, cleaning services, and repair and hire of clothing services, they project a positive annual growth rate of $0.75 \%$ for young French and $3.5 \%$ for French consumers aged at least 65 years old.

${ }^{5}$ At least since the publication of Baumol and Bowen's famous (1966) book economists have realized that manufactured goods have much greater economies of scale and learningby-doing cost saving than do services.
} 
In addition to its policy implications our model also incorporates several technical innovations. We build on the Krugman (1980) model of monopolistic competition with transport costs. This model is useful for showing how trade costs can interact with market size in forming firms' location decisions. We extend Krugman's classic framework in several dimensions. First, we allow for heterogenous agents and non-homothetic preferences. Agents differ by age and older ones spend a larger share of their income on services. We also allow for asymmetric trade costs as well as tariffs. ${ }^{6}$ Finally, in addition to endogenously chosen tariffs we also consider labour migration.

In this framework we derive the following results. First, the age composition of the population has an important determinant on the share of manufacturing firms located within its borders. In particular, the share is decreasing in the average age of the population. The number of manufacturing firms is decreasing in average age in autarky as well, however, the difference is smaller in autarky. Furthermore, the ratio of these differences depends on trade costs. Crucially, the ratio of these changes become very large as trade costs become small. Hence, increased globalization will increase firm delocation effects arising from population aging. In addition, welfare is increasing in the number of domestically produced manufactured goods and is, therefore, decreasing in an aging society. This result does not suggest that trade is worse than autarky, however, it does suggest increased globalization resulting in a reduction in the common trade costs (that, in fact, leaves the total number of manufactured varieties unchanged) will generate differing welfare changes in a young and an old country.

We next consider the role of immigration and tariff policy in ameliorating some of the population-aging effects on trade. Immigration can reduce the demand-driven effects of an aging society as long as it is not too tilted towards older immigrants. If the immigrants are primarily young, if the population

\footnotetext{
${ }^{6}$ Ossa (2011) also analyzes tariff competition and its role in firm delocation. We build on his framework by considering non-homothetic preferences and labour migration.
} 
is initially small, purchased services are a small percentage of total income, or the difference between young and old consumption patterns is small, then a country's share of manufacturing will increase along with increased immigration. Our results on the age of immigrants suggests why countries like Australia, Canada, and New Zealand have stressed a point system (which rewards youth among other things) over family reunification (which can attract elderly parents). ${ }^{7}$

With respect to tariff policy we show that a unilateral tariff increases can increase a country's share of manufacturing firms and increase welfare, however, unilateral tariff increases often generate tariff wars. All else equal, a country with an older average population will lose a tariff war and see a reduction in its share of manufacturing firms. Furthermore, even in the unilateral case, if the tariff revenue is returned to the citizens, then the increased tariff revenue may generate a larger (or smaller) increase in the purchase of services (a luxury good) and diminish (or increase) any firm delocation benefit from a tariff increase.

It has been common in economic models to assume that the marginal (and

\footnotetext{
${ }^{7}$ Canada introduced the points-based system of immigration in 1967 followed by Australia in 1989 and New Zealand in 1991. More recently, Czech Republic, Denmark, Japan, South Korea, Singapore, Sweden, and the UK have introduced the points-based system but on a reduced scale. Australia, Canada and New Zealand consider age as an important factor in order to target young immigrants via their points-based systems. Consequently, there have been less legally admitted immigrants who are 50 or above years of age to these three countries as compared to those legally admitted to the US which relies on a family reunification system prevails. For example, Citizenship and Immigration Canada (2010) provide empirical evidence that there were only about $8 \%$ of all legally admitted immigrants to Canada who were 50 years old or older at admission to Canada during 20022008. Birrell et al. (2006) show that there were only $7 \%$ of immigrants over 46 years old at admission to Australia during 2000-2005. Grangier et al. (2012) indicate that the ratio of old immigrants (50 years of old and above) at admission to New Zealand was just 5\% during 2004-2005. For the US, on the other hand, Carr and Tienda (2013) demonstrates that the immigrant cohort share aged 50 and over at admission to the US rose from $11 \%$ during 1981-1985 to $17 \%$ for 2006-2009 and they provide empirical evidence that family sponsored migration is largely responsible for the increase in legally admitted immigrants aged 50 years old and above to the US during 1981-2009.
} 
average) propensity to consume a good are not dependent on income. These constant income shares, that result from the assumption of homothetic preferences, are frequently employed in the economics literature. Although they have several nice mathematical properties they are repeatedly contradicted by the empirical evidence. From Stone's (1954) seminal work on expenditures through Hunter and Markusen's (1988) groundbreaking work that demonstrates its importance in explaining the pattern of trade, the data continually confirm that preferences are non-homothetic and consumption bundles do change with income. We represent preferences by a Stone-Geary utility function. This representation of non-homothetic preferences is commonly used, in part, because it yields an affine income expansion path, which permits meaningful aggregation. Recent work that introduces non-homothetic preferences into a model of international trade includes Matsuyama (2000), Fieler (2011), Fajgelbaum et al. (2011), Markusen (2013), Caron et al. (2014), and Simonovska (2015). We add to this literature by considering tariff policy and immigration in a trade model with non-homothetic preferences, as well as population aging and combining non-homotheticity with monopolistic competition.

There is a small literature that links the demographic change with international trade, however, these studies differ from ours in that they consider factor market changes as opposed to demand changes. For example, Sayan (2002), Sayan (2005), and Naito and Zhao (2009) show that an aging economy specializes in the capital-intensive sector and incrementally becomes small, while the labour-abundant country specializes in the labour-intensive sector. Cai and Stoyanov (2014) arrive at an analogous result with Sayan (2005) and Naito and Zhao (2009), implying that aging societies would specialize in industries that are age-appreciating-intensive (for example industries that rely more on speech and language abilities) and import age-depreciatingintensive goods that are produced in industries where the production scheme relies mainly on multitasking, memory and speed of information processing. 
Lim and Saner (2011) suggest that population aging may also increase the demand for education in developing and emerging countries and cause a shift in the world demand for education, which in turn may alter the pattern of international trade of educational services.

In the next section we describe the economic environment. In the third section we consider autarky and trade is considered in the fourth section. Immigration policy is the focus of the fifth section and tariff policy is analyzed in the sixth section. Our conclusions are contained in the seventh section.

\section{Economic Environment}

In this section we develop the simplest possible model that can capture our main points. Each of the $L\left(L^{*}\right)$ agents in the home (foreign) country has preferences over manufactured goods, services, and a numeraire good. These preferences can be represented by the following utility function:

$$
u\left(d_{S}, d_{M}, d_{O}\right)=\left(d_{S}+\gamma^{a}\right)^{\alpha}\left(\left[\int_{0}^{N_{M}} d_{M}(z)^{\frac{\sigma-1}{\sigma}} d z\right]^{\frac{\sigma}{\sigma-1}}\right)^{\beta}\left(d_{O}\right)^{1-\alpha-\beta}
$$

The upper tier utility function is of the Stone-Geary variety. ${ }^{8}$ Services are a luxury good and the taste for this luxury, $\gamma^{a}$, depends on the individuals age, $a \in\{g, r\}$. Our idea is that services are more of a luxury for younger (green) individuals and more of a necessity for older (ripe) ones. Hence, $\gamma^{g}>\gamma^{r}>0$. For example, purchases of domestic services, household maintenance, personal care, and even health care are more of a necessity for older individuals, in part, because younger ones can more readily provide many

\footnotetext{
${ }^{8}$ If $\gamma^{a}=0$, then these preferences would be Cobb-Douglass and agents would spend a constant income share $(\alpha, \beta, 1-\alpha-\beta)$ on each of the sectors. As will be seen below, with $\gamma^{a}>0$ services become a luxury good so that the average propensity to consume services is increasing in income.
} 
of these services for themselves. In fact, one could also consider $\gamma^{a}$ as the amount of services that can be enjoyed without being purchased in the market. In addition to the above mentioned personal, health, and maintenance services, they may also consist of socializing with friends or family, reading, or taking walks.

Although empirical work (such as Stone (1954) and Hunter and Markusen (1988) among others) has repeatedly shown that preferences are not homothetic, it is still not obvious what is the best functional form for representing non-homothetic preferences. The Stone-Geary function that we have chosen here is most commonly employed because they permit an affine income expansion path, which permits meaningful aggregation. Still, this functional form is not without restrictions. First, they assume a constant elasticity of substitution between the components of the upper tier utility function. Second, the marginal propensity to consume is independent of income for all individuals above a certain minimum level, therefore, changes in income distribution within a country do not affect aggregate demand when all individuals are above this level. ${ }^{9}$

The sub-utility for the manufactured goods is a constant-elasticity-of-substitution utility function. The parameter $\sigma>1$ expresses the constant pairwise elasticity of substitution. As this parameter is greater than one, no particular variety of the manufactured goods is essential for consumption and, as will be shown below, the value of this subtlety is increasing in the total number of available varieties. (The services and numeraire sector consumptions could also be considered as coming from a constant-elasticity-of-substitution aggregator where the elasticity of substitution is infinite.)

Each firm producing in the monopolistically competitive sector has the same technology:

\footnotetext{
${ }^{9}$ See Chisik et al. (2014) for an alternative environment where within country distribution matters.
} 


$$
\ell_{z}=\frac{q_{z}}{\phi}+f \quad \ell_{z}^{*}=\frac{q_{z}^{*}}{\phi}+f
$$

where $\ell_{z}$ is the amount of labour used in producing good $z, q_{z}$ is the quantity of good $z, \phi$ is the marginal productivity of labour, and $f$ denotes the fixed input requirement. We use the convention that the fixed cost of production, $f$, is paid in terms of labour.

The technology for producing the numeraire good is $\ell_{0}=q_{0}\left(\ell_{0}^{*}=q_{0}^{*}\right.$ in foreign) and the technology for producing services is given by $\ell_{S}=\frac{q_{S}}{\chi}\left(\ell_{S}^{*}=\right.$ $\left.\frac{q_{S}^{*}}{\chi}\right)$ where $(\chi)$ is the labour productivity in services. The labour supply of each country, $L\left(L^{*}\right)$, is assumed to be large enough so that there is positive numeraire and service production in each country. The measure of young individuals in each country is given by $\eta\left(\eta^{*}\right)$ so that $(1-\eta) L$ are the total number of older individuals in the home country. Each individual is endowed with one unit of labour. ${ }^{10}$ As there is no utility for leisure each agent supplies

\footnotetext{
${ }^{10}$ Note that changes in the labour supply $L$ and its age composition $\eta$ can be traced back to conventional drivers of aging, a decrease in fertility or an increase in longevity. To see this, consider an overlapping generations framework where an individual who belongs to generation $t-1$ lives in two periods: $t-1$ and $t$. The first period of her life has a unitary length, while the second one has a length $v \leq 1$, where $v$ reflects a variable longevity. Abstracting from unemployment and retirement, the labour force at time $t$ is thus given $L_{t}=H_{t}+v H_{t-1}$, where $H_{t}$ shows the size of the generation born in $t$. Suppose that successive generations grow at a rate of $h$, which also denotes the fertility rate; thus, $H_{t}=H_{t-1}(1+h)$. Then, we can write the labour force in period $t$ as the following $L_{t}=H_{t-1}(1+v+h)$.

Next, we map the shifts in size and age composition of the labour force onto changes in fertility and longevity. Using the above equation of the labour force, we can write the share of young generation in total labour force as $\eta=\frac{1+h}{1+v+h}$ where both a decrease in fertility $h$ and an increase in longevity $v$ lead to reductions in the share of youth $\eta$ as shown by $-\frac{d \eta}{d h}=-\frac{v}{(1+v+h)^{2}}<0$ and $\frac{d \eta}{d v}=-\frac{(1+h)}{(1+v+h)^{2}}<0$. However, in order to preserve the $L_{t}$, the condition $d v=-d h$ should be satisfied. These two conditions together implies that aging without a change in the size of the population requires a small increase in longevity and an equivalent decrease in fertility.

An increase in total labour supply $L_{t}$ can be driven by an increase in longevity $v$ or an increase in fertility $h$. However, the increase in longevity would also lead to a reduction in demographic share of the youth and the increase in fertility to an increase in it.
} 
their labour inelastically to the firm paying the highest wage. The wage in any sector is, therefore, equal to the price of the numeraire good which is one.

\section{Autarky}

As shown by Dixit and Stiglitz (1977), the set of purchased manufactured goods can be considered as a composite good $D_{M}$ with corresponding aggregate price

$$
P_{M}=\left(\int_{0}^{N_{M}} p_{z}{ }^{1-\sigma} d z\right)^{\frac{1}{1-\sigma}}
$$

Maximization of the upper tier utility function subject to the income constraint $P_{S} d_{S}+P_{M} D_{M}+d_{O}=I$, where $P_{j}$ is the price of good $j \in\{S, M\}$ and $I$ is income, yields the following demand functions.

$$
\begin{gathered}
d_{S}=\operatorname{Max}\left\{0, \frac{\alpha I-P_{S} \gamma^{a}(1-\alpha)}{P_{S}}\right\} \\
d_{M}=\operatorname{Min}\left\{\frac{\beta I}{(1-\alpha) P_{M}}, \frac{\beta\left(I+P_{S} \gamma^{a}\right)}{P_{M}}\right\}
\end{gathered}
$$

Thus, in order to preserve the age composition while increasing the population, a specific relationship between the changes in longevity and fertility is required. To see this, totally differentiate the share of young generation in total labor force $\eta$ to get $\frac{d v}{d h}=\frac{v}{1+h}$, which denotes the corresponding change in $v$ that is required to keep the $\eta$ fixed when $h$ changes. 


$$
d_{O}=\operatorname{Min}\left\{\frac{I(1-\alpha-\beta)}{(1-\alpha)},\left(I+P_{S} \gamma^{a}\right)(1-\alpha-\beta)\right\}
$$

These piecewise-connected demand functions all switch from the first to the second component when

$$
I=\frac{P_{S} \gamma^{a}(1-\alpha)}{\alpha}=\hat{I}
$$

For $I>\hat{I}$ the purchase of services is positive. If labour productivity of services is relatively high, then their price, $P_{S}$ is relatively low and all individuals would purchases services and each individual would consume on the second term in their demand correspondences given above. As will be seen below, after equilibrium prices $\left(P_{S}=\frac{w}{\chi}\right)$ and income $(I=w=1$ from the numeraire good) are derived, a condition on the primitives of the model that guarantees this outcome for all individual is:

$$
\frac{\gamma^{g}(1-\alpha)}{\alpha}<\chi
$$

and we make this assumption throughout our analysis. ${ }^{11}$

Aggregate demand for all goods from the manufacturing sector is then given by

$$
d_{M}=\eta L \frac{\beta\left(I+P_{S} \gamma^{g}\right)}{P_{M}}+(1-\eta) L \frac{\beta\left(I+P_{S} \gamma^{r}\right)}{P_{M}}
$$

so that consumer maximization of the sub-utility function yields demand for

\footnotetext{
${ }^{11}$ As will be clear below, if $\frac{\gamma^{r}(1-\alpha)}{\alpha}<\chi<\frac{\gamma^{g}(1-\alpha)}{\alpha}$, so that only older people buy services, then an older average age population will purchase even more services and less manufactured goods so that all of our results would still hold and even be strengthened.
} 
each variety as

$$
d_{z}=d_{M}\left(\frac{p_{z}}{P_{M}}\right)^{-\sigma}=\frac{L \beta\left[I+P_{S}\left(\eta \gamma^{g}+(1-\eta) \gamma^{r}\right)\right.}{N_{M} p_{z}}
$$

Each manufacturing firm chooses output to maximize profits, and because there is a large number of firms, each takes the output of the other firms and the aggregate price index, $P_{M}$, and consumption, $C_{M}$, as given. This leads to the following pricing rule: $p_{z}=\frac{\sigma}{\phi(\sigma-1)}$. Hence,

$$
q_{z}=d_{z}=\frac{L \beta\left[I+P_{S}\left(\eta \gamma^{g}+(1-\eta) \gamma^{r}\right)\right]}{N_{M} \frac{\sigma}{\phi(\sigma-1)}}
$$

and the gross profits of each firm is given by:

$$
\pi_{z}=r_{z}-l_{z}=p_{z} q_{z}-q_{z}-f=p_{z} q_{z}-q_{z} p_{z} \frac{\sigma-1}{\sigma}-f=\frac{r_{z}}{\sigma}-f
$$

where $r_{z}=d_{M} P_{M}^{\sigma}\left(\phi \frac{\sigma-1}{\sigma}\right)^{\sigma-1}$.

Free entry implies that firms enter until profits are zero. From equation (10) we can derive the total number of firms in autarky as $N_{M}=\frac{L \beta\left[I+P_{S}\left(\eta \gamma^{g}+(1-\eta) \gamma^{r}\right)\right]}{\ell_{z}}$. Finally we note that the total demand for manufacturing labour is given by $\ell_{M}=\int_{0}^{N_{M}} \ell_{z} d z=N_{M} \ell_{z}$.

\section{International Trade}

We now consider international trade in the manufactured goods and the numeraire, however, we assume that services are non-tradable. Whereas the numeraire is traded without cost, manufactured goods have an iceberg trade cost of $\tau=\theta(1+t)>1$. In particular, if one unit is shipped from 
foreign, then $\frac{1}{\tau}$ arrive. The remaining $\frac{\tau-1}{\tau}$ melt away. The term $\theta$ is the common transport cost between home and foreign. The tariff on products that home imports from foreign is $t$. The total trade cost for goods imported into foreign is $\tau^{*}=\theta\left(1+t^{*}\right)>1$. Hence, by restricting tariffs to also be of the iceberg variety we are assuming away any income expenditure effect of tariff revenue. ${ }^{12}$ In this section we take the tariff as given and in the next section we allow countries to choose their tariffs.

Given this formulation the foreign importer price of a manufactured good $z$ that is produced at home is $p_{z}^{*}=\tau^{*} p_{z}$. The home importer price of manufactured good $z$ that is produced in foreign is $p_{z}=\tau p_{z}^{*}$. Hence, we can derive the price index in the home country as:

$$
P_{M}=\left(\int_{0}^{N_{M}+N_{M}^{*}} p_{z}^{1-\sigma} d z\right)^{\frac{1}{1-\sigma}}=N_{M}^{1-\sigma} p_{z}+N_{M}^{* 1-\sigma} \tau p_{z}^{*}
$$

The foreign price index is similar. Using these price indices, home and foreign demands for a home manufactured variety are:

$$
\begin{gathered}
d_{z}=\frac{L \beta\left[I+P_{S}\left(\eta \gamma^{g}+(1-\eta) \gamma^{r}\right) p_{z}{ }^{-\sigma}\right]}{N_{M} p_{z}^{1-\sigma}+N_{M}^{*}\left(\tau p_{z}^{*}\right)^{1-\sigma}} \\
\left(d_{z}\right)^{*}=\frac{L^{*} \beta\left[I^{*}+P_{S}^{*}\left(\eta^{*} \gamma^{g}+\left(1-\eta^{*}\right) \gamma^{r}\right)\left(\tau^{*} p_{z}\right)^{-\sigma}\right]}{N_{M}^{*}\left(p_{z}^{*}\right)^{1-\sigma}+N_{M}\left(\tau^{*} p_{z}\right)^{1-\sigma}}
\end{gathered}
$$

Income is equal to the wage which is given by the price of the freely traded numeraire in both countries. From the given technology, $w=P_{O}=1$, therefore, per capita income is equal to one in home and foreign. The prohibitive trans-

\footnotetext{
${ }^{12}$ This formalization of the combination of a given iceberg transport cost and a chosen iceberg tariff is introduced by Ossa (2011).
} 
port cost on services allows the prices of these non-tradables to differ across borders, however, their simple technology yields $P_{S}=\frac{w}{\chi}=\frac{1}{\chi}=\frac{w^{*}}{A}=P_{S}^{*}$, so that the price of services is the same in both countries. Combining these results with the above demands for each home variety, and noting that $\tau^{*}$ units of a home good need to be shipped for one to arrive in foreign, yields that the total demand for each home manufactured good is:

$$
\begin{gathered}
q_{z}=d_{z}+\left(d_{z}\right)^{*}= \\
\frac{p_{z}{ }^{-\sigma} L \beta\left[\chi+\eta \gamma^{g}+(1-\eta) \gamma^{r}\right]}{\chi\left[N_{M} p_{z}{ }^{1-\sigma}+N_{M}^{*}\left(\tau p_{z}^{*}\right)^{1-\sigma}\right]}+\frac{\tau^{*}\left(\tau^{*} p_{z}\right)^{-\sigma} L^{*} \beta\left[\chi+\eta^{*} \gamma^{g}+\left(1-\eta^{*}\right) \gamma^{r}\right]}{\chi\left[N_{M}^{*}\left(p_{z}^{*}\right)^{1-\sigma}+N_{M}\left(\tau^{*} p_{z}\right)^{1-\sigma}\right]}
\end{gathered}
$$

As in autarky, because there is a large number of firms, each firm considers the price of the other firms and their total number as given, therefore, we again have the pricing rule: $p_{z}=\frac{\sigma}{\phi(\sigma-1)}$. The free entry condition indicates that revenue for each firm must equal total cost for each firm: $p_{z} q_{z}=r_{z}=$ $\ell_{z}=\frac{q_{z}}{\phi}+f$. After substituting in the pricing rule we have that $\frac{\sigma-1}{\sigma}=\frac{q_{z}}{q_{z}+\phi f}$. It is immediate to see that the output of each variety is determined uniquely by $\sigma, \phi, f$ and $w$ and that the price is given by $\sigma, \phi$, and $w$. In particular, in this formulation the wage is determined by the numeraire good and is not affected by country size or the composition of demand, therefore, neither price nor output per firm are determined by market size or demand composition. As we will show below, it is through its effect on the number of varieties that the age composition will have a meaningful effect on the two economies.

Before proceeding it will be useful to introduce the following notation.

$$
\Psi=\frac{\chi+\eta \gamma^{g}+(1-\eta) \gamma^{r}}{\chi} \quad \Psi^{*}=\frac{\chi+\eta^{*} \gamma^{g}+\left(1-\eta^{*}\right) \gamma^{r}}{\chi}
$$


Note that $\beta \Psi L\left(\beta \Psi^{*} L^{*}\right)$ describes the market size for manufactured goods in home (foreign) and we will refer to $\Psi\left(\Psi^{*}\right)$ as a market size parameter. Substituting this notation into equation (13), multiplying each side of that equation by the price of a variety, and using that total revenue equals total cost, we can then write the labour used in producing each home variety as:

$$
\ell_{z}=\frac{\beta}{N_{M}+\tau^{1-\sigma} N_{M}^{*}} \Psi L+\frac{\beta \tau^{* 1-\sigma}}{\tau^{* 1-\sigma} N_{M}+N_{M}^{*}} \Psi^{*} L^{*}
$$

The expression for each foreign variety is similar

$$
\ell_{z}^{*}=\frac{\beta \tau^{1-\sigma}}{N_{M}+\tau^{1-\sigma} N_{M}^{*}} \Psi L+\frac{\beta}{\left(\tau^{* 1-\sigma} N_{M}+N_{M}^{*}\right.} \Psi^{*} L^{*} .
$$

Given that output is determined uniquely by $\sigma, \phi, f$ and $w$ and these are the same in both countries we have that $\ell_{z}=\ell_{z}^{*}$. Using this fact allows us to write the number of varieties of manufactured goods in each country as

$$
\begin{aligned}
& N_{M}=\frac{\beta\left[\left(1-\tau^{1-\sigma}\right) \Psi L-\tau^{1-\sigma}\left(1-\tau^{* 1-\sigma}\right) \Psi^{*} L^{*}\right]}{\ell_{z}\left(1-\tau^{1-\sigma}\right)\left(1-\tau^{* 1-\sigma}\right)}, \\
& N_{M}^{*}=\frac{\beta\left[\left(1-\tau^{* 1-\sigma}\right) \Psi^{*} L^{*}-\tau^{* 1-\sigma}\left(1-\tau^{1-\sigma}\right) \Psi L\right]}{\ell_{z}\left(1-\tau^{1-\sigma}\right)\left(1-\tau^{* 1-\sigma}\right)}
\end{aligned}
$$

These two equations are the focus of our analysis. We begin by looking for conditions on when $N_{M}$ and $N_{M}^{*}$ are both positive. In particular, if $\frac{\Psi L}{\Psi^{*} L^{*}}>\frac{\tau^{1-\sigma}\left(1-\tau^{* 1-\sigma}\right)}{1-\tau^{1-\sigma}}$, then $N_{M}>0$. Otherwise it is zero. Similarly, $N_{M}^{*}>0$ if and only if $\frac{\Psi^{*} L^{*}}{\Psi L}>\frac{\tau^{* 1-\sigma}\left(1-\tau^{1-\sigma}\right)}{1-\tau^{* 1-\sigma}}$. In Krugman (1980), he assumed that $\tau=\tau^{*}$ and that preferences are homothetic so that $\Psi=\Psi^{*}=1$. In this case, if $\tau=\tau^{*}$ approaches one from above, then it is straightforward to verify that both $N_{M}$ and $N_{M}^{*}$ could not be strictly positive unless $L=L^{*}$. Hence, 
all manufacturing activity would accumulate in the larger economy. This is also true in our framework, however, the definition of market size depends not only the population, but also the age composition. Note that $\Psi$ is decreasing in the age of the population (increasing in $\eta$ ) so that a younger population increases the domestic market size for manufactured goods.

We now consider the relative number of manufactured varieties that are produced in the home country. To this end we define $\hat{N}_{M}=\frac{N_{M}}{N_{M}+N_{M}^{*}}$. We then have

$$
\begin{gathered}
\hat{N}_{M}=0 \quad \text { for } \frac{\Psi L}{\Psi^{*} L^{*}} \leq \frac{\tau^{1-\sigma}\left(1-\tau^{* 1-\sigma}\right)}{1-\tau^{1-\sigma}} \\
\hat{N}_{M}=\frac{\frac{\Psi L}{\Psi L+\Psi^{*}}\left(1-\tau^{1-\sigma} \tau^{* 1-\sigma}\right)-\tau^{1-\sigma}}{\left(1-\tau^{1-\sigma}\right)\left(1-\tau^{* 1-\sigma}\right)} \text { for } \frac{1-\tau^{* 1-\sigma}}{\tau^{* 1-\sigma}\left(1-\tau^{1-\sigma}\right)}<\frac{\Psi L}{\Psi^{*} L^{*}}>\frac{\tau^{1-\sigma}\left(1-\tau^{* 1-\sigma}\right)}{1-\tau^{1-\sigma}} \\
\hat{N}_{M}=1 \quad \text { for } \frac{\Psi L}{\Psi^{*} L^{*}} \geq \frac{1-\tau^{* 1-\sigma}}{\tau^{* 1-\sigma}\left(1-\tau^{1-\sigma}\right)}
\end{gathered}
$$

Examination of the above equations reveals that $\hat{N}_{M}$ is weakly increasing in both $\Psi$ and $L$. In particular, it is strictly increasing when both countries produce manufactured goods (as in the middle term in the above equations) and it is non-changing otherwise. As shown above, the area where $\hat{N}_{M}=$ $\{0,1\}$ also depends on both $\Psi$ and $L$. From the expression for $\Psi$ we see that $\Psi$ is decreasing in the age of the population (increasing in $\eta$ ) so that a younger population increases the market for manufactured goods. Hence, we have that the share of manufactured goods produced by a country is also decreasing in the age of their population. We summarize these results in Proposition 1 below. 
Proposition 1. A country with a smaller population can have a larger effective home market and be a net exporter of manufactured goods if they have a younger population. If both countries export manufactured goods, then an increase in the average age of the population will decrease that countries share of the total manufactured varieties. Furthermore, an increase in the average age of the population will increase the necessary size of the population so that manufacturing output is positive.

Proposition 1 is our first main result in that it highlights the relationship between age and the pattern of trade. Our result is novel in that it depends only on demand considerations.

If we look further at equation (19) we see that the share of manufactured goods produced by a country increases more rapidly than its share of total market size, which is defined as $\frac{\Psi L}{\Psi L+\Psi^{*} L^{*}}$. To see this fact note because $\sigma>1$ it must be the case that $\left(1-\tau^{1-\sigma} \tau^{* 1-\sigma}\right)>\left(1-\tau^{1-\sigma}\right)\left(1+\tau^{* 1-\sigma}\right)$. Furthermore, the change of market share of manufactured goods with respect to changes in population size is given by:

$$
\frac{\partial \hat{N}_{M}}{\partial L}=\frac{\Psi^{2} L}{\left(\Psi L+\Psi^{*} L^{*}\right)^{2}} \frac{\left(1-\tau^{1-\sigma} \tau^{* 1-\sigma}\right)}{\left(1-\tau^{1-\sigma}\right)\left(1-\tau^{* 1-\sigma}\right)}
$$

As noted above $\Psi$ is increasing in $\eta$, therefore, an increase in population will have a larger affect on the share of manufactured goods if the population is younger. We summarize the results in proposition 2 .

Proposition 2. If both countries produce manufactured goods, then the share of manufactured goods produced by a country increases more rapidly than an increase in their relative market size. Furthermore, when population increases, the share of manufactured goods produced by a country increases by a greater amount when the population is younger. 
We illustrate the first part of proposition 2 with the following figure 1.

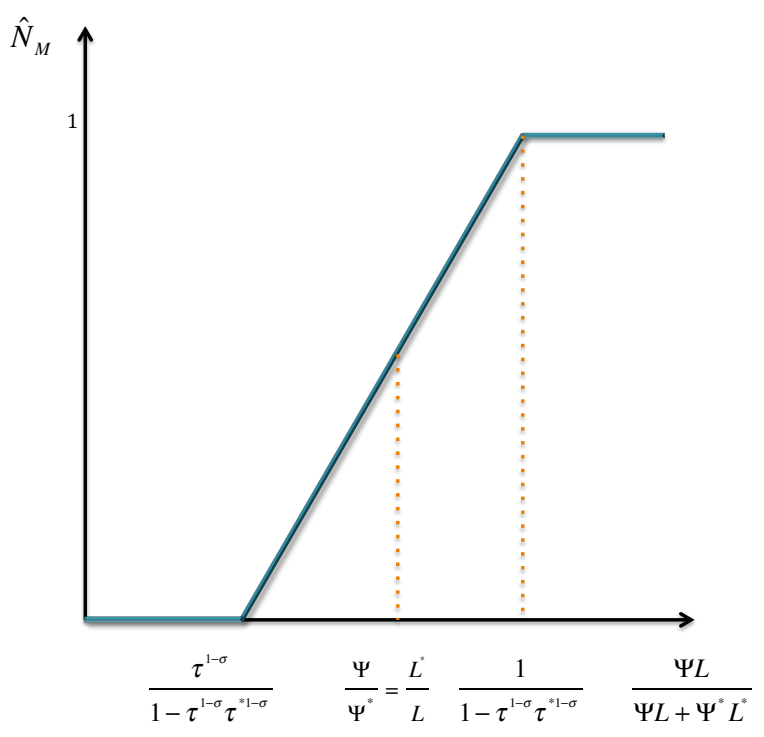

First, note the bounds or breakpoints where each country is producing positive amounts of manufactured goods. We also see that the share of manufactured goods is increasing at a faster rate than the market share. Notice as well that this increase depends on the trade costs. Finally notice that even when their market size is equal the countries may not have equal manufacturing shares. They are equal only if the trade costs are equal. 
Propositions 1 and 2 describe how an aging population can reduce the share of exportable manufactured goods that a country produces. The idea is that, because these goods have a higher value added than the numeraire good, this reduction generates a loss in welfare. This loss comes about through the reduction in the home price index. In particular, looking at equations (17) and (18) we see that following an increase in the average age of the home population the increase in the foreign varieties is only $\tau^{* 1-\sigma}<1$ times the absolute value of the decrease in home varieties: $\frac{\partial N_{M}}{\partial \Psi}=-\left(\tau^{* 1-\sigma}\right) \frac{\partial N_{M}^{*}}{\partial \Psi}$. Hence, if $\tau$ and $\tau^{*}$ are not too different, then the price index given in equation (11) must increase following the reduction in $N_{M}$. Substituting the equilibrium consumption levels, prices, and income into equation (1) yields that social welfare can be written as $W=\eta W^{g}+(1-\eta) W^{r}$, where

$$
W^{a}=\left[\alpha\left(\chi+\gamma^{a}\right)\right]^{\alpha}\left[\frac{\beta\left(\chi+\gamma^{a}\right)}{\chi P_{M}}\right]^{\beta}\left[\frac{\left(\chi+\gamma^{a}\right)(1-\alpha-\beta)}{\chi}\right]^{1-\alpha-\beta} .
$$

Hence, an increase in the price index must decrease welfare of both age groups in the population.

It is interesting to compare the different effects of an aging population in trade and in autarky. From equation (10) we know that the total number of domestic manufacturing firms in autarky is given by $N_{M}^{A}=\frac{L \beta \Psi}{\ell_{z}}$ and in trade it is given by equation (17). As population ages the difference between these changes is given by the term reflecting the foreign trade cost in the denominator.

$$
\frac{\partial N_{M}^{A}}{\partial \eta}=\frac{L \beta}{\ell_{z}} \frac{\gamma^{g}-\gamma^{r}}{\chi}<\frac{L \beta}{\ell_{z}\left(1-\tau^{* 1-\sigma}\right)} \frac{\gamma^{g}-\gamma^{r}}{\chi}=\frac{\partial N_{M}}{\partial \eta} .
$$

Hence, the change is larger in the trade case. Furthermore, this difference become larger as the trade cost becomes smaller (becoming infinite as $\tau$ 
approaches one). Increased globalization resulting in lower trade costs will, therefore, magnify the negative firm delocation effect resulting form an aging population. We summarize this result in proposition 3.

Proposition 3. An increase in the average age of a country will decrease its number of manufacturing firms by a larger amount under trade than under autarky. The ratio of these differences is monotonically decreasing in trade costs and approaches infinity (one) as trade costs approach one (infinity). Increased globalization, as reflected in lower trade costs, will magnify the firm delocation effect of an aging society.

We now consider how a country can influence its share of manufactured goods by their choice of trade and immigration policy.

\section{$5 \quad$ Immigration Policy}

As noted in the previous section a country can affect their share of manufacturing production by increasing their market size or by changing their trade costs. We begin by considering a change in market size.

Apart from policies that encourage child rearing, an increase in market size may be produced by a more open immigration policy. An important caveat is that the effect of immigration depends on the age composition of the immigrants. In particular, the change in the home market size is given by the change in two terms: $\Psi$ and $L$. Immigration clearly increases L, however, the effect on $\Psi$ depends on the change in the relative number of young people. The change in the home market size can be decomposed into two terms as follows:

$$
\frac{\partial \Psi L}{\partial L}=\left(\gamma^{G}-\gamma^{R}\right) \frac{d \eta}{d L} L+\Psi
$$


where $\left(\gamma^{G}-\gamma^{R}\right) \frac{d \eta}{d L}$ shows how $\Psi$ changes with respect to immigration. This first term is the age composition effect and the second term is the population effect. If the immigration policy accepts at least as many young as old people, then $\frac{d \eta}{d L} \geq 0$ and the immigration policy will increase the home market size. A more interesting case is if the influx is tilted towards older people, so that $\frac{d \eta}{d L}<0$. In this case if $\left(\gamma^{G}-\gamma^{R}\right)$ is large, then increased immigration may paradoxically reduce the size of the home market for manufactured goods and generate a reduction in the share of home manufacturing firms. Hence, for immigration to increase the home market size requires

$$
\frac{d \eta}{d L}>\frac{-\Psi}{\left(\gamma^{G}-\gamma^{R}\right) L}
$$

Even if the average of the population increases age $\left(\frac{d \eta}{d L}<0\right)$ the above condition may be satisfied if the population is small in number $(L)$, the difference between young and old consumption patterns $\left(\gamma^{G}-\gamma^{R}\right)$ is small or the amount of purchased services is low. This third condition refers to the term in the numerator $(\Psi)$ and this term is larger if $\gamma^{G}$ and $\gamma^{R}$ are both larger and/or labour productivity in services $(\chi)$ is lower. Either of these conditions will reduce the amount of purchased services. We state these results as proposition 4 below.

Proposition 4. Immigration will increase the home country's share of manufacturing output if it does not increase the average age of the population. Even if the average age increases, the home country's share of manufacturing will increase along with increased immigration if the population is small, purchased services are a small percentage of total income, or the difference between young and old consumption patterns is small.

The above result may help explain why many countries have instituted a point system for immigration and have reduced the role of family reunifica- 
tion. That is, a point system tends to reward youth and family reunification can be used to bring elderly parents.

An additional aspect of proposition 4 is that it suggests larger countries, or those with with greater labour productivity in services have the most reason to be selective in their immigration policy. As it is usually countries that have a combination of these aspects (large $L$ and large $\chi$ ) that are most desirable for immigrants, the restrictions in proposition 4 have economic significance.

\section{$6 \quad$ Tariff Policy}

An additional way in which a country can affect its home market size is through trade policy. We now consider tariffs.

In analyzing tariff policy remember that the trade cost for the home country is $\tau=\theta(1+t)$. Hence, tariffs magnify the effect of any transport cost. Looking at equation (19) for the home market shares in manufacturing, or at figure 1, we can see that an increase in the home tariff will reduce the minimum home market share at which home manufacturing output is positive $\left(N_{M}>0\right)$ and at which foreign output is zero $\left(N_{M}=1\right)$. This change is illustrated in figure 2 below. 


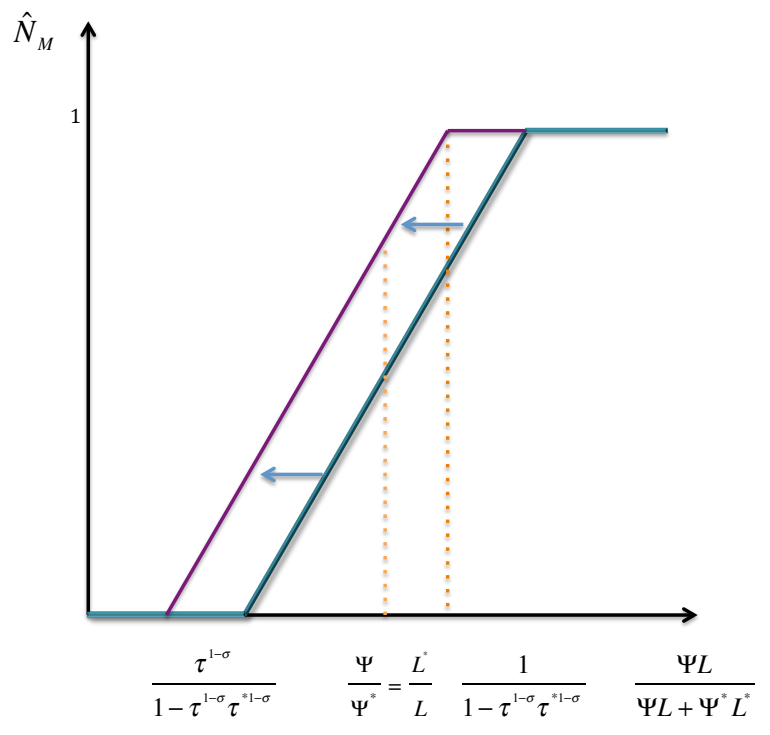

From figure 2 we can see that the shift of the breakpoints also shifts the segment of $N_{M}$ where both countries produce manufactured goods back towards the origin. Hence, an increase in the home tariff must also increase the share of home manufacturing when both countries produce manufacturing goods. We can also see this result analytically from equation (19). It occurs because the increased home tariff makes it more expensive to serve the home market relative to foreign. For any home market size more firms would want to locate in home and export to foreign. The home share of manufacturing 
output must, therefore, increase.

Rather than differentiating equation (19) it will prove more helpful to analyze the changes in home and foreign manufacturing separately as given in equations (17) and (18). Differentiating each with respect to the home tariff we have:

$$
\frac{\partial N_{M}}{\partial t}=\frac{\beta(\sigma-1) \tau^{-\sigma} \theta \Psi^{*} L^{*}}{\ell_{z}\left(1-\tau^{1-\sigma}\right)^{2}}>0 ; \quad \frac{\partial N_{M}^{*}}{\partial t}=\frac{\beta(1-\sigma) \tau^{-\sigma} \theta \Psi^{*} L^{*}}{\ell_{z}\left(1-\tau^{1-\sigma}\right)^{2}}<0
$$

An interesting implication of equation (25) is that the changes are fully offsetting. That is, an increase in the home country tariff increases the number of firms locating in home and decreases the number locating in foreign by the same amount. The total number of firms stays the same. Furthermore, the effect is independent of the home market size.

If we then substitute equations (25) into the price index given in equation (11) we see that an increase in the home tariff reduces the price index. This result occurs because the number of home and foreign firms each enters with a negative exponent, so that more firms reduces the index, and the number of foreign firms is multiplied by the home trade cost, $\tau$. Hence, shifting firms from foreign to home must reduce the price index. Finally, from equation (21), this change must increase welfare. In fact, it would be unilaterally optimal for home to raise its tariff until all manufacturing firms were located in the home country. We summarize the results of this section in proposition 5 below.

Proposition 5. An increase in the home country tariff does not change the total number of manufacturing firms. It increases the number of home firms and decreases the number of foreign firms by equal amounts. Home welfare is strictly increasing in the home tariff as long as foreign manufacturing is positive (and it is non-negative otherwise). The effect of the home tariff on 
firm location is increasing in the foreign market size but is independent of home market size.

Although proposition 5 suggests that a country could increase the number of domestically produce manufactured goods and domestic welfare by unilaterally increasing its import tariff, it also indicates that the policy has strong beggar-thy-neighbour implications. Any manufacturing gain to the home country is offset by the loss to the foreign country. There is an additional loss in world welfare as a result of the iceberg trade cost.

This additional loss is relevant for two reasons. First, if the foreign country retaliates against the tariff increase, then it is likely that both countries will be worse off in terms of welfare. To see the change in the number of firms in each country consider the case where the tariff is the same in both countries. Taking the derivative of equation (19) with respect to this common tariff yields that an increase in the common tariff will increase a country's share of manufacturing firms if and only if it has a larger relative market size. Referring back to equations (17) and (18) we also see that a change in this common tariff will not change the total number of firms. Foreseeing retaliation against its unilateral tariff increase a country should, therefore, only increase its tariff if it has the larger domestic market size. In as much as the tariff is being considered as an antidote to a reduction in market size (as a result of the demand shift that accompanies an aging population), a country that is rendered smaller as a result of the demand shift would be most likely to lose from a tariff war that accompanied any unilateral tariff increase. We state this observation as corollary 6 below.

Corollary 6. An increase in the common tariff will reduce the share of manufacturing firms in the country with the smaller domestic market size and increase it in the other country. All things equal, a country with a greater average age is more likely to lose from a tariff war.

In addition to the potential for retaliation there is an other limitation to 
mitigating the loss of manufacturing share through tariff policy. The additional limitation is the dispensation of the tariff proceeds. In the current framework, they have no effect on the model because they are assumed to melt away in the ocean. In as much as they are returned to the people in the country they could affect the composition of demand. Although preferences are non-homothetic the marginal propensity to consume out of additional income does not depend on income as long as the assumption in equation (6) is satisfied. If it is not satisfied, then young people would not purchase services and the results of the model would be strengthened because an aging population would have even higher average purchases of services. If the tariff revenue were sizable, then, in this case, it could generate a market demand for services by young people who would otherwise not purchase services solely out of wage income. Hence, any increase in manufacturing market share would be reduced by this added income effect. Although more of a theoretical curiosity, it is even possible for a unilateral tariff increase to decrease a county's manufacturing share if the income effect is large enough. Alternatively, if the tariff revenue was small, so that the young still did not consume services (if the assumption in equation 6 is not satisfied), then the domestic aggregate demand for manufactured goods would increase more rapidly in tariff revenue than would services and the firm delocation effect of the tariff would be augmented, however, by a smaller amount for an older country.

\section{Conclusions}

We consider the role of demand driven changes arising from population aging and how they affect the pattern of international trade as well as trade and immigration policy. An aging society can see a welfare reducing reduction in its share of manufacturing output and this reduction is magnified by a decrease in trade costs (an increase in globalization). Immigration can ameliorate this outcome if it is directed towards younger immigrants. A unilateral 
tariff increase can also reduce firm delocation from aging country, however, a reciprocated tariff increase will unambiguously harm the country with the older average population.

\section{References}

Baumol, W. J. and W. G. Bowen (1966). Performing arts, the economic dilemma: A study of problems common to theater, opera, music and dance. New York: Twentieth Century Fund.

Birrell, R., L. Hawthorne, and S. Richardson (2006). Evaluation of the general skilled migration categories. Department of Immigration and Multicultural Affairs (March).

Cai, J. and A. Stoyanov (2014). Population aging and comparative advantage. York University, Department of Economics, Working Paper, 15-01.

Caron, J., T. Fally, and J. R. Markusen (2014). International trade puzzles: A solution linking production and preferences. The Quarterly Journal of Economics 129(3), 1501-1552.

Carr, S. and M. Tienda (2013). Family sponsorship and late-age immigration in aging America: Revised and expanded estimates of chained migration. Population Research and Policy Review 32(6), 825-849.

Chisik, R., B. Battaile, and H. Onder (2014). The distribution of natural resource rents and the Dutch disease. Ryerson University, Department of Economics, Working Paper, 041.

Citizenship and Immigration Canada (2010). Evaluation of the Federal Skilled Workers Program. 
Desvaux, G., B. Regout, E. Greenberg, G. Green, A. Harbola, and J. Leite (2010). Meeting the 2030 French consumer. McKinsey Consumer and Shopper Insights (May), 1-68.

Dixit, A. K. and J. E. Stiglitz (1977). Monopolistic competition and optimum product diversity. The American Economic Review 67(3), 297-308.

Fajgelbaum, P. D., G. M. Grossman, and E. Helpman (2011). Income distribution, product quality, and international trade. Journal of Political Economy 119(4), 721-765.

Fieler, A. C. (2011). Non-homotheticity and bilateral trade: Evidence and a quantitative explanation. Econometrica 79(4), 1069-1101.

Grangier, J., R. Hodgson, and K. McLeod (2012). Points of difference: Does the skilled migrant category points system predict wages? Wellington: Integration of Immigrants Programme.

Hunter, L. and J. Markusen (1988). Per-Capita Income as a Determinant of Trade. In R. Feenstra (ed): Empirical Methods for International Trade. Cambridge, MA, MIT Press.

Krugman, P. (1980). Scale economies, product differentiation, and the pattern of trade. The American Economic Review 70 (5), 950-959.

Lim, A. H. and R. Saner (2011). Rethinking trade in education services: A wake up call for trade negotiators. Journal of World Trade 45(5), 9931034 .

Markusen, J. R. (2013). Putting per-capita income back into trade theory. Journal of International Economics 90(2), 255-265.

Matsuyama, K. (2000). A Ricardian model with a continuum of goods under non-homothetic preferences: Demand complementarities, income dis- 
tribution, and North-South trade. Journal of Political Economy 108(6), 1093-1120.

Naito, T. and L. Zhao (2009). Aging, transitional dynamics, and gains from trade. Journal of Economic Dynamics and Control 33(8), 1531-1542.

Oliveira Martins, J., F. Gonand, P. Antolín, C. De la Maisonneuve, and K.-Y. Yoo (2005). The impact of ageing on demand, factor markets and growth. OECD Economics Department Working Paper, 420.

Ossa, R. (2011). A new trade theory of GATT/WTO negotiations. Journal of Political Economy 119(1), 122-152.

Sayan, S. (2002). Dynamic Heckscher-Ohlin results from a 2x2x2x2 overlapping generations model with unequal population growth rates. Department of Economics, Discussion Paper, 02-01.

Sayan, S. (2005). Heckscher-Ohlin revisited: Implications of differential population dynamics for trade within an overlapping generations framework. Journal of Economic Dynamics and Control 29(9), 1471-1493.

Simonovska, I. (2015). Income differences and prices of tradables: Insights from an online retailer. Review of Economic Studies (forthcoming).

Statistics Canada (2013). Survey of Household Spending (SHS).

Stone, R. (1954). Linear expenditure systems and demand analysis: An application to the pattern of British demand. The Economic Journal 64 (255), $511-527$.

United Nations (2013). World Population Ageing. 